\title{
Opened Approaches on Treatment and Herbs' Location in Iran
}

\author{
Ebrahim Alinia Ahandani ${ }^{1 *}$, Hossnieh Kafshdar Jalali ${ }^{2}$ and Chonoor Mohammadi ${ }^{3}$ \\ ${ }^{1}$ Department of Biochemistry, Payame Noor University, Tehran,Iran \\ ${ }^{2}$ Department of Microbiology, Islamic Azad University, Lahijan,Iran \\ ${ }^{3}$ Department of Biology, University of Soran Kurdistan, Kurdistan, Iraq
}

*Corresponding author: Ebrahim Alinia Ahandani, Department of Biochemistry, Payame Noor University, Tehran, P.0.BOX 193953697, Iran.

To Cite This Article: Alinia-Ahandani E, Kafshdar-Jalali H, Mohammadi Ch. Opened Approaches on Treatment and Herbs' Location in Iran. Am J Biomed Sci \& Res. 2019 - 5(5). AJBSR.MS.ID.000953. DOI: 10.34297/AJBSR.2019.05.000953.

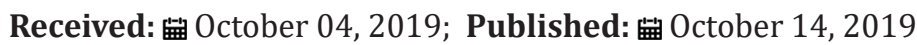

\begin{abstract}
Medicinal plants as a kind of forgotten healthcare gadgets in recent years must be considered as much as before. Iran was a place where had a lot of herb species (over 2300 from 8000) conserving treatment in the world and now is changing the old way (chemical usage). However, realizing the drawbacks of allopathic medicine, the world is turning back to herbal medicines, too. Presently, about $80 \%$ of the world population is still dependent on medicinal plants for health care and $20 \%$ of the drugs in pharmaceutical firms are of plant origin, either extracted from the plants or synthetic derivatives of these plant species. In this paper we briefly focused on the role of phytochemical sources like Alkaloids, Tannins, Terpenes, Flavonoids and etc. Also, we express some notes around economical value of medicinal plants for future analysis. Some strategies were told for developing this industry in Iran and world too.
\end{abstract}

Keywords: Iran; Medicinal Plants; Healthcare; Drug; Alkaloids

\section{Importance of Medicinal Plants}

Long before the development of modern medicines, Iran in ancient times, was entirely dependent on herbal medicines for health care. Many scripts carry elaborate prescriptions of herbal medicines for treating very complex disorders [1,2]. Iran was the leader in health care through Ayurveda. Apart from such systematic therapies, specific herbal therapies developed by individuals were used for treating the ills and these secret therapies were passed on from the older generation to the younger generation, without disclosing them to the outsiders. Even today, Medicinal plants play a remarkable role in Iran [3-6]. A similar practice was also prevalent in China and many other countries in Asia and Africa. With the progress of science, allopathic medicine gained prominence over herbal medicines. With larger commercial interest, the western countries promoted modern drugs, inspite of its high cost and side effects [7-9]. However, realizing the drawbacks of allopathic medicine, the world is turning back to herbs. Recently, about $80 \%$ of the world population is still dependent on herbs for health care and $20 \%$ of the drugs in pharmaceutical companies are of plant origin, either extracted from the plants or synthetic derivatives of these plant species [10-13].

In China, over 5000 plant species are used in drugs and traditional medicines, while over 2300 species are known for their traditional medicinal value in Iran. In addition to medicinal characteristics, some of these species are also used as tonics. Ginsing, one of the most popular species used as a tonic, is widely grown in China and Korea. In 1991, the value of Ginsing sold in USA and Asian region was over US\$215 million and China had a lion's share of $40 \%$ [14-17]. The assessed annual market value of the plant-based drug is US\$43,000 million and it is expected to rise to US\$ 3 trillion over the next two decades.

In Iran, around 15 million people from 80, traditional herbal medicines are the only alternative source, due to easy accessibility and lower price. This sector also provides employment to over one million traditional healers and Vaidyas in the country [18-20,4]. Thus, sustainable development of herbs provides an excellent opportunity to take advantage of the expanding market, while ensuring a steady supply to local communities $(6,8,10,12)$. 


\section{Phytochemical role of Metabolites in some Herbs}

Phytochemicals are compounds that existed naturally in plants. They contribute to the colour, flavour and smell of plants. In addition, they form part of a plant's natural defense mechanism against diseases. Their remedial values to human health and disease prevention have been reported $(21,22,5)$. The most usually encountered secondary metabolites of herbs (phytochemicals) are alkaloids, tannins, terpenes, flavonoids, saponins, anthraquinones, cardiac glycosides, and cyanogenic glycosides. The pharmacological and other beneficial effects of antinutritional features in herbs have been reviewed by Soetan $[21,17]$. The presence of these secondary metabolites in plants possibly explains the various uses of plants for traditional medicine. Alkaloids are basic natural products occurring in many plants. They are generally found in the form of salts with organic acids and they are haemolytically active and are also toxic to micro-organisms $(22,7,8,18,23)$. Alkaloids, comprising a large group of nitrogenous compounds are widely used as therapeutic agents in the management of cancer [20,24].

Alkaloids also interfere with cell division. In some cases, researchers isolated an alkaloid from Hibiscus sabdariffa and demonstrated its ability to prevent mutagenesis. Alkaloids and their synthetic derivatives are used as basic medicinal agents for their analgesic, antiplasmodic and bactericidal effects $[1,3,22]$. Tannins are complex phenolic polymers which can bind to proteins and carbohydrates resulting in reduction in digestibility of these macromolecules and thus inhibition of microbial growth $[19,16]$. Tannins from the bark, roots and other parts of many plants especially Euphorbiaceae are used to treat cells that have gone neoplastic $[12,3,4]$. Tannins are widely used, in herbal medicine, to treat wounds and to arrest bleeding [5-7]. The presence of tannins in plants implies they may have astringent properties and, in addition, could quicken the healing of wounds and burns $[14,25,26]$. Tannins are reported to have astringent properties on mucous membranes $[4,6,9,27,28,6]$.

Terpenes, also known as isoprenoids $[10,15]$ are the largest class of phytonutrients in green foods, soy plants and grains. Animals have evolved to utilise these compounds for hormonal and growth regulatory functions (vitamin A) and, as it is now being understood, the presence of these molecules in human tissues also provides a measure of protection from certain diseases, especially those related to chronic damage and growth dysregulation. Terpenes have a unique antioxidant activity in their interaction with free radicals. Terpenes react with free radicals by partitioning themselves into fatty membranes by virtue their long carbon side chain $[3,927,29]$.

Flavonoids are a group of phytochemicals found in varying amounts in foods and medicinal plants which have been shown to exert potent antioxidant activity against superoxide radicals $[6,10,30]$. Its consumption has been documented not to be associated with mortality due to coronary heart disease. This may be as a result of its antioxidant activity and subsequent inhibitions of low-density lipoproteins (LDL) oxidation known to have been attributed to the dietary and supplemental intake of flavonoids and other micronutrients. Epidemiologic studies indicate an inverse relationship between intake of dietary flavonoids and coronary artherosclerotic disease $[6,8,11,16]$. Flavonoids have strong anticancer activity and protect against different levels of carcinogenesis $[9,16,18,29]$. Flavonoids have been shown to have hepatoprotective, antibacterial, anti-inflammatory, antiallergic, antimutagenic, antiviral, antineoplastic, antithrombotic and vasodilatory activity $[12,16,19]$. Flavonoids were also shown to inhibit microbes which are resistant to antibiotics $[1,2,27]$.

\section{Production of Medicinal Herbs}

Generally, the villagers acquire fundamental science about the use of different herbs from their elders and gather them fresh from their gardens or nearby forests, whenever they need them. However, with deforestation and commercialisation of agriculture, many medicinal plants are not easily included. So, with the progress of allopathic systems, doctors discourage their patients from using herbal medicines [22-28]. Increasingly, most of the ayurvedic medicines produced by the pharmaceutical companies are used as backup therapies, tonics or to counteract the side effects of allopathic medicines, resulting in loss of faith in the system.

Recently, a large number of companies are included in bulk production of herbal drugs in Iran. As most of these firms do not have their own source of raw materials required for processing, they are dependent on the natural forests. These firms have been engaging the local forest dwellers to gather raw material from the forests. The assessed value of medicinal plants extracted for drug production is over US $\$ 300$ million. The raw material for most of these products come from the natural forests for which the industry barely pays the cost of labour. This has resulted in the destruction of a large number of herbal species leading to their extinction around the world.

Recently, very few species have been exploited for commercial production in Iran. Among them, Opium is the most remarkable crop, cultivated for production of morphine over 23000 ha land in Guilan, Mazandaran. and Golestan. Senna is another crop cultivated in Yazd, Kurdistan and Kerman, covering around 2800 ha, yielding about 6000 tons of leaves and pods. Psyllium (Isabgul) is another important crop grown on 35000 ha in North parts and Dashte Moghan area of Ardabil and southern parts of Iran yielding 30,000ton seeds. Out of this, about $82-85 \%$ of the produce can be exported. Periwrinkle (Catharanthus roseus) for extraction of Raubasine, yam bearing Diosgenin (Dioscorea composita) and Sinkona (Cinchona calysaya) are the other important species grown commercially on non-forest lands in Iran and Iran western areas for medicinal characteristics apart from the large number of herbs and trees having medicinal properties. 
A few more plant species brought under commercial production during recent years are Menthol (Mentha arvensis), Safed musli (Chlorophytum tuberosum), Aloe vera (Aloe barbadensis) and Anola (Emblica officinalis). But in the absence of an assured market and fluctuating price, great uncertainty prevails in the field [30].

\section{Some remarkable Strategies for Developing of Herbal Medicine Industry}

Recently, over 100 million ha of wastelands are not only lying idle, depriving the poor of opportunities for income generation but also posing a serious threat to the ecosystem and environment $[1,4,8]$. Such talented lands can be used for growing medicinal plants, which are in good request. Commercial cultivation of medicinal plants can be promoted by establishing a linkage with bulk consumers $[17,18,20]$. For successful development of herbal drugs industry in the country, the following steps are suggested.

a) Identification of plant species having medicinal characteristics and establishment of data banks and herbariums.

b) Conservation of medicinal plants in their natural habitats -- in-situ and in protected regionsS (ex-situ)

c) Selecting superior germplasm based on laboratory analysis and field studies, for domestication and commercial production.

d) Regulation and standardization of propagation and cultivation actions for producing superior quality herbal extracts, which can be accepted by growers.

e) Validation of the uses of different medicinal plants in curing various disorders, standardization of the protocols and documentation.

f) Strengthening of doing research to find potential herbal drugs to cure different diseases, especially modern emerging illnesses.

g) Patenting of the traditional actions and germplasm. Facilitation counters can be funded to assist the local healers to patent their cures.

h) Introduction of herbal medicine as an integral issue in medical colleges and universities dealing with various systems of drugs.

i) Extending the use of different medicinal plants through specific prescriptions, social marketing and mass awareness.

j) Following local healers and Ayurveda practitioners through sharing of science, networking, supply of superior quality germplasm and linkage with growers for preparation of raw extracts.

k) Including a legal linkage between the growers, bulk consumers and pharmaceutical industries or companies at national and international stages. l) Reforming and replacment in the Government policies to support investigations and development on herbal drugs and to curb over-exploitation of herbs in natural forests.

Serious attempts have been made by the Government of Iran and several State provinces to promote the growing and processing of herbs both in Government and private sectors over the last two decades $[21,26]$. However, inspite of having a bright future, particularly, as a leader in the international market, there has not been any major breakthrough in this sector. The major bottleneck seems to be the linkage between the producers and processors $[5,14,29]$. While the natural sources of herbs are fast depleting, the processors are not willing to encourage the farmers to take up the scientific production of raw materials. The major issues are higher cost of production as compared to the material collected illegally from the forests and unstable demand for the produce $[13,16,20]$. As marketing of unknown brands of ayurvedic products is extremely hard, it is difficult for the growers to organise processing and marketing of these products $[11,15,19]$. Increasingly, encouraging growers to take up knowledge production of herbal species, with buyback guarantee is crucial to vast this sector $[21,25]$.

Fortunately, the Government of Iran has already established an independent politic to promote herbal drugs part in the country. This country can coordinate the above activities to boost the industry and capture the global opportunities in the near future $[13,21,22]$.

\section{References}

1. Kirtikar KR, Basu BD (1998) Indian Medicinal Plants: Vol I DehraDun: Bishen Singh Mahendra Pal Singh. pp. 327.

2. Ahmed MM, Zagazig (1995) Flavonoids from the leaves of Hibiscus cannabinus. J Pharm Sci 4(2): 44-48.

3. Alinia Ahandani E, M Fazilati, Z Alizadeh, A Boghozian (2018) The introduction of some mushrooms as an effective source of medicines in Iran Northern. Biol Med 10(5): 1-5.

4. Mohamad M, Yolande S, Raed R (2004) Hepatoprotective activity of Centaurium on acetaminophen induced hepatotoxicity in rats. Phytother Res 18(5): 431-433.

5. Maruthappan V, Sakthi shree K (2009) Hepatoprotective effect of Azadirachta indica (neem) leaves against alcohol induced liver injury in albino rats. J of Pharmacy Research 2(4): 655-659.

6. Alinia Ahandani E, M Fazilati, A Boghozian, M Alinia Ahandani (2019) Effect of ultraviolet (UV) radiation bonds on growth and chlorophyll content of Dracocephalum moldavica L herb. J Biomol Res Ther 8(1): 1000172 .

7. Alinia Ahandani E, H Nazem, A Boghozian, Z Alizadeh (2019) Hepatitis and some effective herbs: A review. EAS J Parasitol Infect Dis 1(1): 20-27.

8. Lin CC, Yen MH, Lo TS, Lin JM (1998) Evaluation of the hepatoprotective and antioxidant activity of Boehmeria nivea var. nivea and B. nivea var tenacissima. J Ethnopharmacol 60(1): 9-17.

9. Vinodhini Singanan, Malairajan Singanan, Hazeena Begum (2007) The hepatoprotective effect of Bael leaves (Aegle marmelos) in alcohol induced liver injury in albino rats. Int J Sci \& Tech 2: 83-92.

10. Zafar R, Ali SM (1998) Anti-hepatotoxic effects of root and root callus extracts of Cichorium intybus L. J Ethnopharmacol 63, 63(3): 227-231. 
11. Katende AB, Paul Ssegawa, Ann Birnie (1999) Wild food plants and mushrooms of uganda. Relma Technical Handbook No.19. pp 240, 266, 392.

12. Shankar D, Majumdar B (1997) Beyond the Biodiversity Convention: the challenges facing the biocultural heritage of India's medicinal plants. Medicinal Plants for Forest Conservation and Health Care-Nonwood Forest Products Series No. 11. FAO, Rome. p. 87-99.

13. Ahandani EA (2018) Medicinal plants effective on pregnancy, infections during pregnancy, and fetal infections. J Pharm Sci Res p.3.

14. Sadykov AS, Sadykov AA, Ismailav AI, Isacv KI (1971) Isolation of some substances from Hibiscus cannabinus leaves. Khim Prir Soedin 7(2) 215-216.

15. Gauniyal AK, Singh AK, Virmani OP (1991) Major Medicinal Plants as Foreign Exchange Earner. Yojana. p. 14-18.

16. Asima Chatterjee, Satyesh Chandra Pakrashi (1992) The Treatise medicinal plants, Vol 2, New Delhi: Publication and Information Directorate p.178.

17. Asadi Samani M, N Kafash Farkhad, N Azimi, A Fasihi, E Alinia Ahandani, et al. (2015) Medicinal plants with hepatoprotective activity in Iranian folk medicine. Asian Pac. J Trop Biomed 5(2): 146-157.

18. Torress Durain PV, Miranda Zamora R, Paredes Carbajal MC, Mascher D, Ble Castillo J, et al. (1999) Studies on the preventive effect of Spirulina maxima on fatty liver development by carbon tetrachloride in the rat. J Ethnopharmacol 64(2): 141-147.

19. Prema Veeraraghavan (2000) Expert consultant, CPCSEA, OECD Guideline no. pp. 420.

20. Ibnusaud I, Rajashekharan R, Philip T, Thyomas S (1998) Convenient method for large scale isolation of Hibiscus acid, Patent -US-6127553. p.6
21. Osman AM, EI GarbyYounes M, Ataa FM (1978) Chemical examination of local plants. Part xii. Some constituents from the leaves of Egyptian Hibiscus cannabinus. Egypt J Chem 19: 633-641.

22. Saxena AK, Singh B, Anand K (1993) Hepatoprotective effects of Eclipta alba on sub cellular levels in rats. J Ethnopharmacol 40(3): 155-161.

23. Agbor AG, Oben JE, Ngogang JY (2001). Effect of water extract of Hibiscus cannabinus leaves on phenylhydrazine induced haemolytic anaemia. Paper Presented at the 8th symposium of the Cameroon Society for Biochemistry and Molecular Biology, University of Dschang p. 25-26.

24. Agbor AG, Oben JE, Ngogang JY (2005) Hepatoprotective activity of Hibiscus cannabinus (Linn.) against carbon tetrachloride and paracetamol induced liver damage in Rats. Pak J Biological Sci 8(10): 1397-1401.

25. Rajesh SV, Rajkapoor B, Senthil kumar, Raju K (2009) Effect of Clausena Dentate (willd.) Roem M. against paracetamol induced hepatotoxicity in rats. Pak J Pharm Sci 22(1): 90-93.

26. Pakundina ZP, Lien NT (1976) Flavonoids form Hibiscus cannabinus leaves. Khim Prir Soedin 12(2): 258.

27. Ahandani EA, MRA Gawwad, A Yavari (2013) Extraction and preparation of psoralen from different plant part of psoralea corylifolia and psoralen increasing with some elicitors. J Plant Biol Res 2: 25-37.

28. Osman AM, EI Garby Younes M, Ataa FM (1975) Chemical examination of local plants. Part ix, Comparative studies of the constituents of some parts of Egyptian Hibiscus cannabinus. Indian J Chem 13: 535-536.

29. Kurian JC (1995) Plant That Heal, Oriental Watchman Publishing House, VoII, Pune India. p. 183

30. Ebrahim Alinia Ahandani, Zahra Alizadeh-Terepoei, Ani Boghozian (2019) Positive Role of Green Tea as An Anti-Cancer Biomedical Source in Iran Northern. Am J Biomed Sci \& Res 5(1): 39-42. 